\title{
Comparative Investigation of the Structure, Phase Composition, and Mechanical Properties of Ni-Based High-Temperature Alloys Manufactured by Different Methods
}

\author{
A. Yu. Tokmacheva-Kolobova ${ }^{a, b}, *$, S. S. Manokhin ${ }^{a, c, * *}$, V. N. Sanin ${ }^{d, * * *}$, \\ D. M. Ikornikov ${ }^{d, * * * *}$, D. E. Andreev ${ }^{d, * * * * *}$, M. G. Tokmachev ${ }^{e, * * * * * *}$, \\ A. F. Zverev ${ }^{c, * * * * * * *}$, and E. G. Kolobova ${ }^{a, c, * * * * * * * *}$ \\ ${ }^{a}$ Institute of Problems of Chemical Physics, Russian Academy of Sciences, Chernogolovka, Moscow oblast, 142432 Russia \\ ${ }^{b}$ National University of Science and Technology MISiS, Moscow, 119049 Russia \\ ${ }^{c}$ Belgorod State National Research University, Belgorod, 308015 Russia \\ ${ }^{d}$ Merzhanov Institute of Structural Macrokinetics and Materials Science, Russian Academy of Sciences, \\ Chernogolovka, Moscow oblast, 142432 Russia \\ ${ }^{e}$ Moscow State University, Moscow, 119991, Russia \\ *e-mail: anastasiia.misis@gmail.com \\ **e-mail:manohin@bk.ru \\ ***e-mail:svn@ism.ac.ru \\ ****e-mail:iko@ism.ac.ru \\ *****e-mail:ade@ism.ac.ru \\ ******e-mail:miket@mail.ru \\ *******e-mail:zverev@bsu.edu.ru \\ $* * * * * * * * e-$ mail: kolobova@icp.ac.ru
}

Received December 11, 2018; revised December 11, 2018; accepted April 12, 2019

\begin{abstract}
A comprehensive comparative study of the structure, phase composition, and mechanical properties of heat-resistant nickel-based $\mathrm{Ni}-\mathrm{Cr}-(\mathrm{X})$ alloys produced by the methods of traditional metallurgy and self-propagating high-temperature synthesis (SHS metallurgy) is carried out. With the purpose of formation of the submicrocrystalline structure, a longitudinal rolling and post-deformation annealing of the cast alloy is performed. The microstructure of the heat-resistant alloys is investigated by the SEM and TEM methods. It is shown that the cast alloy has a recrystallized structure with the mean grain size of $\sim 1 \mu \mathrm{m}$ and the particles of chromium carbides have a size of $\sim 1-3 \mu \mathrm{m}$. After rolling and subsequent annealing $\left(750^{\circ} \mathrm{C} / 1 \mathrm{~h}\right)$, the average grain size is reduced to $0.43 \mu \mathrm{m}$ and the formation of dispersed particles of carbides $100 \mathrm{~nm}$ in size is observed. The structure of the alloy obtained by SHS metallurgy is dendritic, and particles of $\mathrm{W}$ and $\mathrm{Cr}$ are absent. When $0.1 \mathrm{wt} \%$ carbon powder is added to the initial powder mixture for SHS synthesis, formation of the network of W and Cr particles is observed along the boundaries of dendrite colonies. It is found that the SHS Ni-based heat-resistant alloy similar in composition to commercial cast alloy is characterized by improved mechanical properties and increased heat resistance compared to the cast alloy in both the coarsegrained and the submicrocrystalline state. Adding the carbon powder to the powder mixture for SHS leads to a further increase in the resistance to high-temperature deformation owing to formation of the carbide phase impeding the movement of dislocations and grain boundary creeping processes.
\end{abstract}

Keywords: high-resistant nickel alloys, SHS metallurgy, microstructure, mechanical properties

DOI: $10.1134 /$ S2075113320030430

\section{INTRODUCTION}

Heat-resistant nickel-based alloys are widely used as construction materials in aerospace engineering, including fabrication of the details of the hot zone of gas turbine engines owing to sufficiently high thermal stability of structure and creep strength at elevated temperatures along with high corrosion stability [1-
6]. The working temperature of nickel- and cobaltbased alloys with intermetallic or solid-solution strengthening varies from 750 (Inconel 718, VZh172) to $1100^{\circ} \mathrm{C}$ (VZh145, HS188) [6-9].

In this work, alloy of the $\mathrm{Ni}-\mathrm{Cr}-(\mathrm{X})$ system was studied by the example of KhN60VT brand (VZh98). It is known that VZh98 alloy possesses a fairly high 
ductility at room and elevated temperatures and does not require additional complex thermal treatment. The phase composition of the alloy is represented by alloyed Ni-based $\gamma$ solid solution and the particles of the secondary carbide phase $\left(\mathrm{W}_{6} \mathrm{C}\right.$ and $\left.\mathrm{Cr}_{23} \mathrm{C}_{6}\right)$. It is known that disperse particles of secondary phases (carbides, nitrides, oxides, and others), in particular, those along grain boundaries, increase the high-temperature strength of metal polycrystals, because they prevent migration of grain boundaries and propagation of recrystallization and grain-boundary creeping at elevated and high temperatures [2]. The grainboundary carbide particles have the same positive influence on the high-temperature strength of the considered alloys $[1,5]$, which are extremely sensitive to variations of structure, phase composition, and distribution of the phase precipitations along the bulk material. In order to provide high high-temperature strength of these alloys, it is preferable that grainboundary precipitations have a globular shape and submicron size and are homogeneously distributed in the bulk material. In addition, during the choice and optimization of the chemical composition of the alloys, it must be considered that an excess increase in the carbon content may result in excess precipitation of chromium-based carbide phases and a decrease in high-temperature strength and heat resistance also because of the depletion of the matrix in alloying elements (primarily chromium). The platelike or needlelike shape of carbides and their nonuniform distribution along grain boundaries may result in embrittlement, which decreases the service life of the structural elements of this alloy at elevated temperatures. It is known that the carbides of $\mathrm{M}_{6} \mathrm{C}$ type are more stable at high temperatures than $\mathrm{M}_{23} \mathrm{C}_{6}$; therefore, precipitation of the $\mathrm{W}_{6} \mathrm{C}$ carbide phase along grain boundaries is more favorable for the increase in high-temperature strength $[1,6,10]$.

Owing to the consistent trend to the increase in the cost of energy source materials and initial components of heat-resistant nickel-based alloys, energy and resource saving technologies for the fabrication of such materials are currently being developed. Selfpropagating high-temperature synthesis (SHS) is one of the promising methods for the design of new hightemperature metal and ceramic materials [11, 12]. In this work, the method for the fabrication of cast materials in the combustion mode, which was referred to as the SHS technology of high-temperature melts [13] or SHS metallurgy [14-16], was used for the fabrication of $\mathrm{Ni}-\mathrm{Cr}-\mathrm{W}$ alloy. Employment of highly exothermic SHS compositions of thermite type gives temperatures which are sufficient for the fabrication of the melts of the products of combustion (higher than $2500^{\circ} \mathrm{C}$ ). At this temperature, the target product (metal melt) and the slag phase (metal oxide reducing agent) exist in the liquid phase and there is a gravitational separation (delayering) of the liquid metal and slag melts under the force of gravity. The ingots of cast high-melting compounds [12, 17], solid alloys, oxide and composition materials $[18,19]$, and also their weldings [20] are formed after cooling depending on the composition of the mixture and the conditions of synthesis.

The advantages of SHS metallurgy of cast heatresistant materials are the following:

- simple equipment and minimum energy consumption;

- achievement of high temperatures necessary for the fabrication of heat-resistant alloys owing to internal chemical heat sources;

- high efficiency caused by a high combustion rate (time of synthesis is less than 2-3 min);

- and fabrication of heat-resistant materials with specific composition and structure.

In contrast to the counterparts prepared through conventional electrometallurgy, SHS materials possess a lower content of uncontrollable impurities and more perfect crystal structure, which provides higher physicomechanical characteristics of such materials [21-23].

The aim of this work is to compare the effect of structure and phase composition on mechanical characteristics of heat-resistant alloys of the $\mathrm{Ni}-\mathrm{Cr}-(\mathrm{X})$ system fabricated through traditional and SHS metallurgy.

\section{MATERIALS AND METHODS}

To carry out comparative studies, an industrial alloy of KhN60VT brand (VZh98) was chosen [24]. The specified chemical composition of the alloy is given in Table 1 and the results of X-ray microanalysis of the initial industrial alloy (states I and II) and the alloys prepared through SHS synthesis (states III and IV) in a scanning electron microscope (SEM) equipped with an EDAX energy-dispersive adapter are given there. The instrumental measurement error of the concentration of elements was $1 \mathrm{wt} \%$.

The VZh98 industrial alloy under study was in the form of sheets $3 \mathrm{~mm}$ in thickness in the as-received state. To dissolve secondary phases and homogenize the chemical composition of the alloy, annealing at $1200^{\circ} \mathrm{C}$ and subsequent quenching in water were carried out. To form the submicrocrystalline (SMC) structure, the specimens $10 \times 5 \times 1 \mathrm{~mm}$ in size were exposed to longitudinal rolling in a TRIO-450 mill at room temperature at the rate of $10^{-2} \mathrm{~m} / \mathrm{s}$. The recrystallized structure in the specimens after rolling was formed through annealing in the air in muffle furnace at the temperatures of $650-750^{\circ} \mathrm{C}$ for $1 \mathrm{~h}$.

Using the SHS metallurgy method with the technical-grade powder mixture of $\mathrm{Ni}, \mathrm{Cr}, \mathrm{W}$, and $\mathrm{Fe}$ oxides and addition of carbon (graphite), as well as aluminum of PA-4 brand as a reducing agent, alloys of the Ni$\mathrm{Cr}-\mathrm{W}$ system, which are similar in composition to ini- 
Table 1. Elemental composition of the investigated $\mathrm{Ni}-\mathrm{Cr}-(\mathrm{X})$ alloy, wt $\%$

\begin{tabular}{l|c|c|c|c|c|c|c|c|c}
\multicolumn{1}{c|}{ Alloy } & $\mathrm{Ni}$ & $\mathrm{Cr}$ & $\mathrm{W}$ & $\mathrm{Fe}$ & $\mathrm{Ti}$ & $\mathrm{Al}$ & $\mathrm{Mn}$ & $\mathrm{C}$ & $\mathrm{Si}$ \\
\hline $\begin{array}{l}\text { Specified composition of the VZh98 indus- } \\
\text { trial alloy }\end{array}$ & Main & $23.5-26.5$ & $13-16$ & $<4$ & $0.3-0.7$ & $<0.5$ & $<0.5$ & $<0.10$ & $<0.8$ \\
$\begin{array}{l}\text { Results of analysis of VZh98 industrial cast } \\
\text { alloy in initial state (I)* and after additional } \\
\text { thermomechanical treatment (II)** }\end{array}$ & Main & 25 & 14 & 1 & 0.2 & - & $<1$ & $<1$ & $<1$ \\
SHS alloy (III)*** & Main & 19 & 12 & 5 & - & 5 & 1 & 0.04 & 1 \\
SHS alloy (IV)*** & Main & 31 & 20 & 4 & - & 0.5 & 0.4 & 0.08 & - \\
\hline
\end{tabular}

\footnotetext{
* Industrial cast alloy in initial state.

** Initial cast alloy after additional thermomechanical treatment for the formation of submicrocrystalline (SMC) structure.

*** The alloy fabricated through SHS metallurgy.

****The alloy fabricated through SHS metallurgy with addition of $0.1 \mathrm{wt} \%$ of powdered carbon.
}

tial VZh98 industrial alloy, were fabricated. The mean particle size of the initial powder mixture was less than $100 \mu \mathrm{m}$. The powders were mixed in a planetary mixer for $15 \mathrm{~min}$. To enhance gravitational separation and convective mixing of the melt, the alloy was synthesized in a centrifugal SHS unit at the overload from 1 to $500 \mathrm{~g}$ [17]. A ceramic (corundum) mold with the diameter of $40 \mathrm{~mm}$ inside a graphite mold was used for the synthesis. Employment of two molds eliminated spreading of the melt upon rotation of the rotor of the centrifugal SHS unit. The diagram of $\mathrm{SH}$ synthesis of the cast materials and its main stages are described in detail in [16-19].

Microhardness measurements of the specimens (micropolished sections after etching) were carried out using a tetrahedron with a square base (Vickers method) on a DM8 digital hardness meter at the load of $100 \mathrm{~g}$.

Mechanical compression tests of the specimens in the form of a parallelepiped with the dimensions of $8 \times 8 \times 12 \mathrm{~mm}$ were performed at room and high $\left(1000^{\circ} \mathrm{C}\right)$ temperatures on an Instron $300 \mathrm{LX}$ universal hydraulic test machine at the rates of deformation of $10^{-2}$ to $10^{-4} \mathrm{~s}^{-1}$.

Structural studies were carried out at longitudinal and transverse cross sections of the blanks. The microstructure and phase composition of the specimens was studied using transmission electron microscopy (TEM) on a Tecnai GF20 S-TWIN microscope at the accelerating voltage of $200 \mathrm{kV}$ in the transmission electron microscopy and scanning transmission electron microscopy (STEM) modes. The distribution of chemical elements in the alloy was determined through X-ray energy-dispersive microanalysis in the STEM mode using an EDAX adapter and Tecnai Imaging \& Analysis software. Quantitative processing of high-resolution electron images and electron diffraction patterns was carried out using the Digital Micrograph 2.0.2 computer program. Studies on Quanta FEG 600 and NovaNanoSem 450 scanning electron microscopes (SEM) were carried out at the accelerating voltage of $30 \mathrm{kV}$.
The mean size of the elements of grain-subgrain structure on TEM images was determined by the secant method according to the results of measurements of at least 300 grains. ImageScope software was used for calculations. The averaged histograms of size distribution of microstructural elements and all necessary characteristics of the obtained distributions for statistical processing were determined according to the histograms of grain size distribution of horizontal and vertical secants for the specimens in each state.

Using the backscattered electron diffraction method (EBSD) in SEM, which is based on the identification of diffraction patterns in the form of Kikuchi lines, the histograms of the grain-boundary angle distribution were plotted.

The specimens for TEM were prepared on an AQ300L electroerosion setup. The cut disks $3 \mathrm{~mm}$ in diameter were processed in two stages. At the first stage, mechanical polishing on abrasive disks to the plate thickness of $100-150 \mu \mathrm{m}$ was used for thinning. It is known that structural distortions are observed at the depth of up to $12-75 \mu \mathrm{m}$ at rough polishing, while this depth amounts to $2.5-25 \mu \mathrm{m}$ at fine polishing. A LaboPol-5 setup (Struers) was used at the second stage of foil preparation. Because thinning is performed from two sides at the second stage of the final step of thin foil preparation (on a TenuPol-5 setup for electrolytic jet polishing using an $80 \mathrm{~mL} \mathrm{HClO}_{4}+90 \mathrm{~mL}$ $\mathrm{H}_{2} \mathrm{O}+730 \mathrm{~mL} \mathrm{C}_{2} \mathrm{H}_{5} \mathrm{OH}$ electrolyte at the temperature of $-10^{\circ} \mathrm{C}$ and the voltage of $U=27 \mathrm{~V}$ ), no artifacts associated with mechanical polishing at the initial stages of foil preparation should be observed in the foil under study.

\section{RESULTS AND DISCUSSION \\ Initial Industrial Cast Alloy (State I)}

SEM images of the microstructure of the alloy under study after casting (state I) are given in Figs. 1a and $1 \mathrm{~b}$. The microstructure of the alloy consists of grains whose shape is similar to equiaxial and tungsten and chromium carbide particles with the sizes of $\sim 1-$ 
(a)
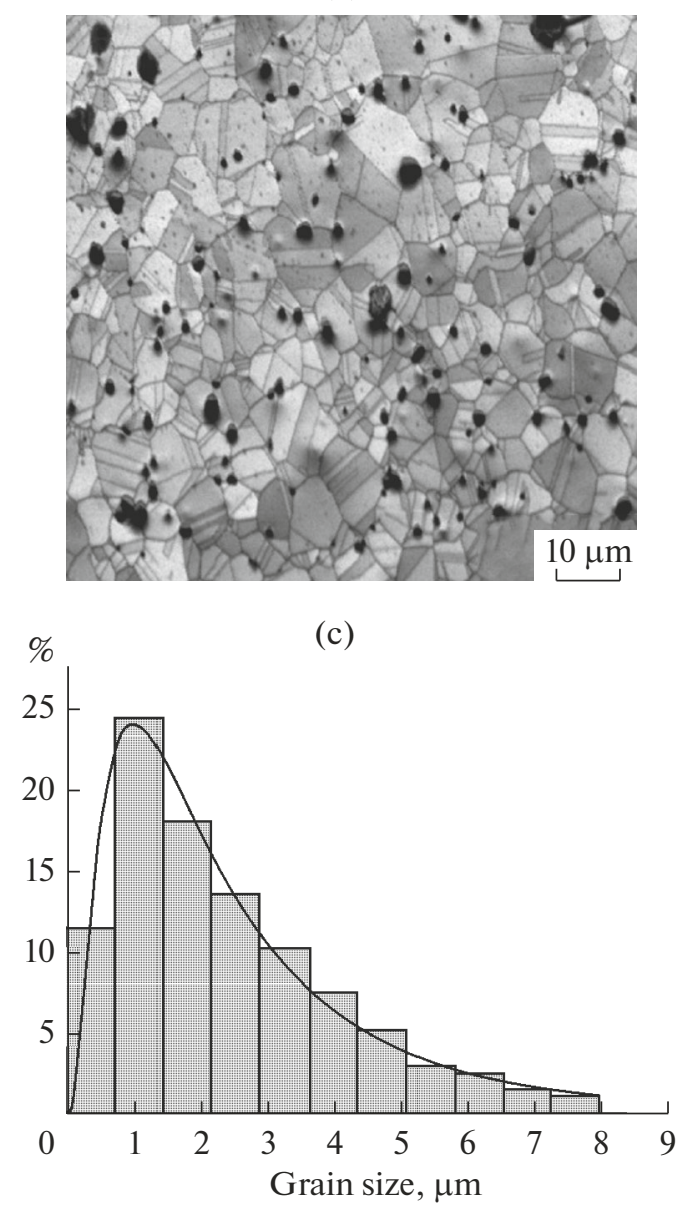

(b)
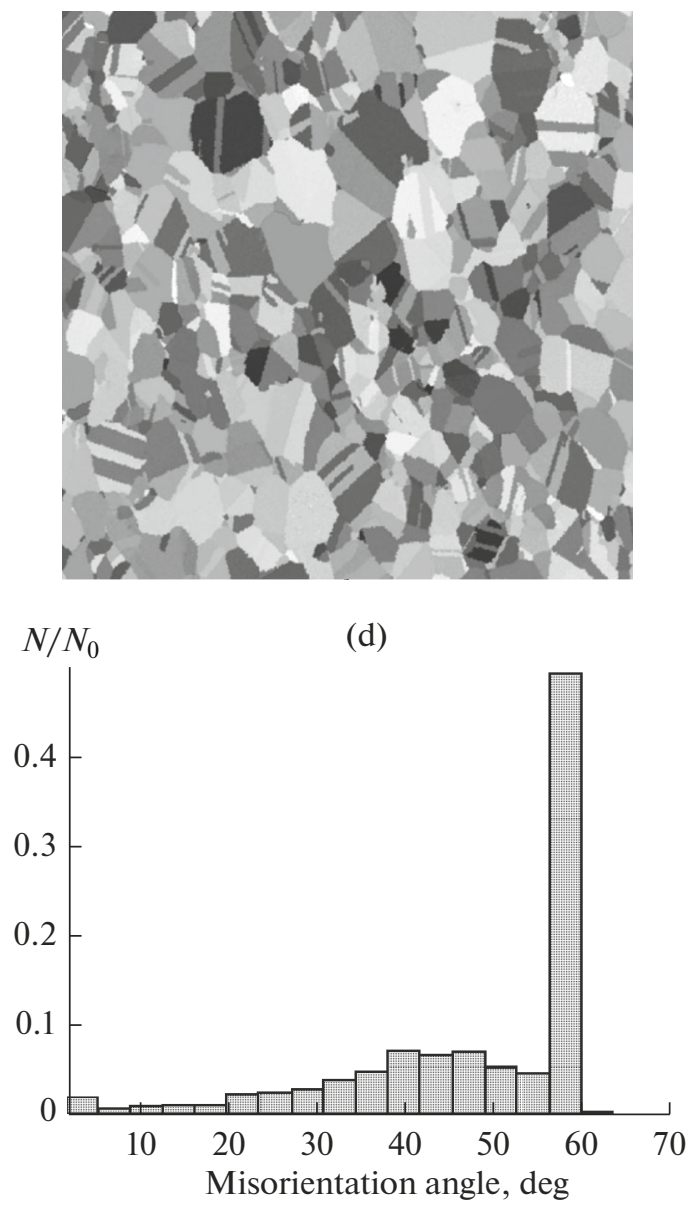

Fig. 1. Microstructure of $\mathrm{Ni}-\mathrm{Cr}-\mathrm{W}$ commercial cast alloy in as-received condition (position I): (a) SEM image in backscattered electrons; (b) electron backscatter diffraction map in the color spectrum of the crystallographic triangle of FCC nickel lattice; (c) grain size distribution; (d) histogram of misorientations of grain boundaries.

$3 \mu \mathrm{m}$. The grain distribution is similar to lognormal (Fig. 1c). The mathematical expectation of the grain size is $2.89 \pm 0.16 \mu \mathrm{m}$, the median of the distribution is $2.05 \mu \mathrm{m}$, and the mode is $1.03 \mu \mathrm{m}$ (the size of the sample is 1332 measurements). The fraction of lowangle boundaries is $7 \%$ and that of high-angle boundaries is $93 \%$; the grain disordering spectrum is characterized by a peak at $60^{\circ}$ (Fig. 1d). It is known that this fact corresponds to the presence of a large number of grain boundaries of twin type, which usually have a rectangular shape.

\section{Cast Alloy after Rolling and Formation of SMC Structure (State II)}

After rolling to the degree of deformation of $\varepsilon=$ $80 \%$ at elevated temperature $\left(600^{\circ} \mathrm{C}\right)$, the microstructure of material is characterized by the features of a nonequilibrium high-defect state. A high density of strain defects is observed; there is no contrast of grain boundaries, which can indicate the presence of elastic stress fields on the strain defects of the crystal lattice. In the state after rolling and subsequent annealing at $650^{\circ} \mathrm{C} / 1 \mathrm{~h}$, domains in which primary recrystallization with simultaneous evolution of secondary disperse carbide particles starts are observed.

The fully recrystallized structure is observed only after annealing at $750^{\circ} \mathrm{C}$ for $1 \mathrm{~h}$ (Figs. 2a, 2b).

The grain size distribution is similar to lognormal (Fig. 2c). The mathematical expectation of the grain size is $0.68 \pm 0.02 \mu \mathrm{m}$, the distribution median is $0.58 \mu \mathrm{m}$, and the mode is $0.43 \mu \mathrm{m}$ (the size of the sample is 2872 measurements). The fraction of low-angle boundaries is $6 \%$ and that of high-angle boundaries is $94 \%$.

In analogy to the initial state, there is misorientation at $60^{\circ}$ (twin boundaries) on the grain-boundary misorientation diagrams. There are also special largeangle boundaries with predomination of misorientation at $\sim 37-38^{\circ}$ (Fig. 2d). Such recrystallized state after rolling and annealing at $750^{\circ} \mathrm{C} / 1 \mathrm{~h}$ was chosen for comparative study of mechanical properties at elevated temperatures. 
(a)
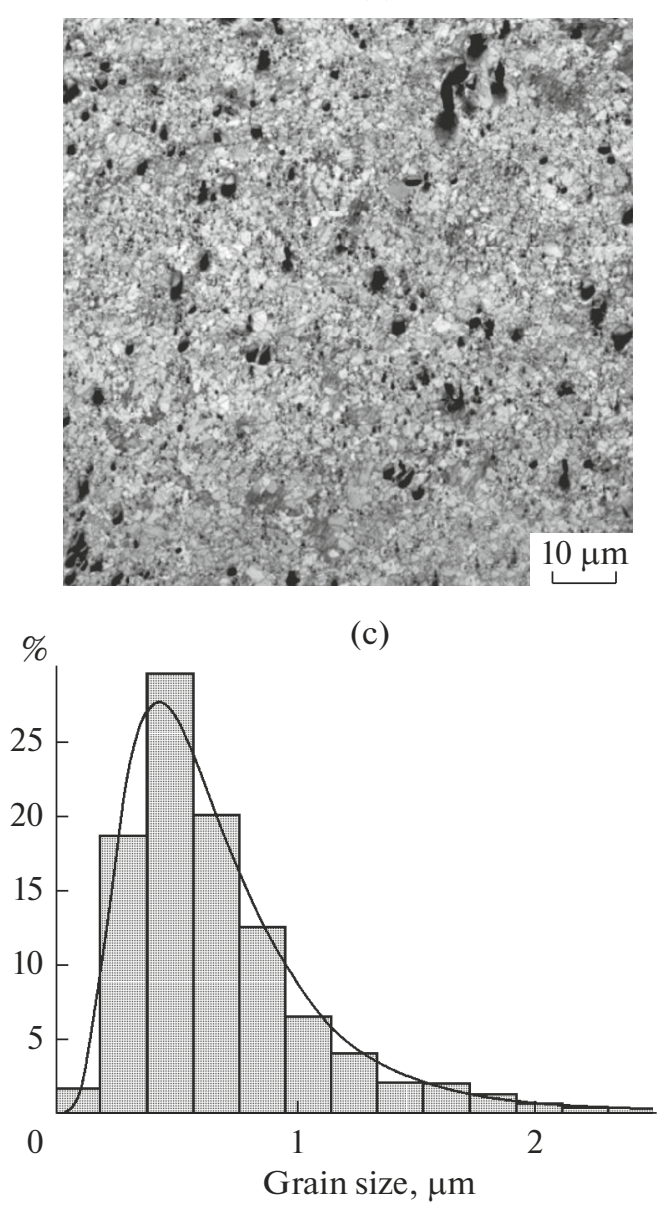

(b)
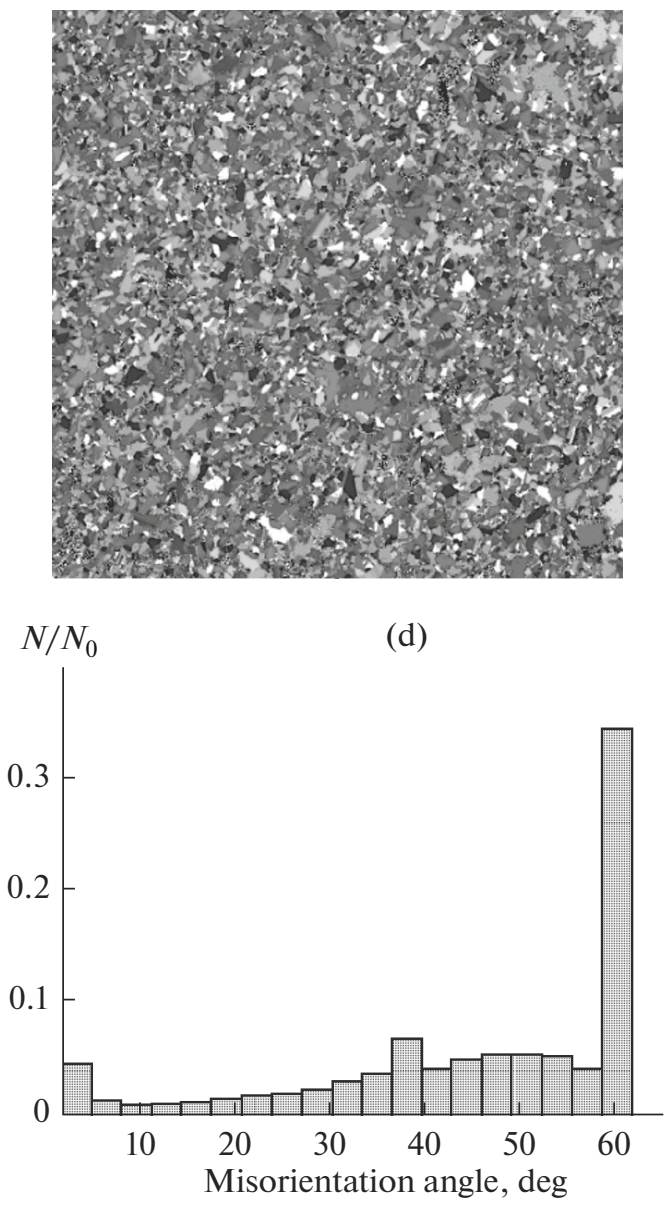

Fig. 2. Microstructure of $\mathrm{Ni}-\mathrm{Cr}-\mathrm{W}$ commercial cast alloy after rolling and annealing $750^{\circ} \mathrm{C} / 1 \mathrm{~h}$ (position II): (a) SEM image in backscattered electrons; (b) electron backscatter diffraction map in the color spectrum of the crystallographic triangle of FCC nickel lattice; (c) grain size distribution; (d) histogram of misorientations of grain boundaries.

After annealing at $750^{\circ} \mathrm{C}$, as at the initial stage of recrystallization, disperse $(\sim 100 \mathrm{~nm})$ chromium and tungsten carbides precipitated on grain boundaries are observed (Fig. 3).

\section{Alloy Prepared through SHS Metallurgy (State III)}

At the first stage of the study of applicability of SHS metallurgy, the alloy specimens similar in composition to VZh98 without additional alloying with carbon were fabricated. The structure of SHS alloy is characterized by clearly defined dendritic columns, which represent a nickel-based solid solution (Fig. 4); however, in contrast to the industrial cast alloy in various states, it does not have $\mathrm{W}$ and $\mathrm{Cr}$ particles. As follows from the data in Table 1, the composition of the synthesized SHS alloy corresponds to the composition of the VZh98 industrial alloy, which allows for a valid comparison of mechanical characteristics of the industrial cast alloy and the alloys synthesized using SHS metallurgy.

\section{Alloy Prepared Using SHS Metallurgy with Addition of 0.1 wt \% Powder Carbon (State IV)}

Addition of carbon to the initial powder mixture for SH synthesis brings its content to $0.1 \mathrm{wt} \%$ in the synthesized specimens. This results in the formation of a network of discrete interlayers of lamellar type on the boundaries of dendritic columns in the alloy structure (Fig. 5). An increased concentration of alloying elements ( $\mathrm{W}$ and $\mathrm{Cr}$ ), whose precipitations are uniformly distributed in the bulk and along the boundaries of dendritic columns, was detected in this network using energy-dispersive $\mathrm{X}$-ray microanalysis.

\section{Mechanical Properties}

The data on the mechanical characteristics of the industrial alloy and the alloy prepared through SHS metallurgy are given in Table 2 .

It is clear that the industrial alloy with SMC structure (state II) and the alloy prepared using SHS metallurgy with additional alloying with carbon (state IV) 

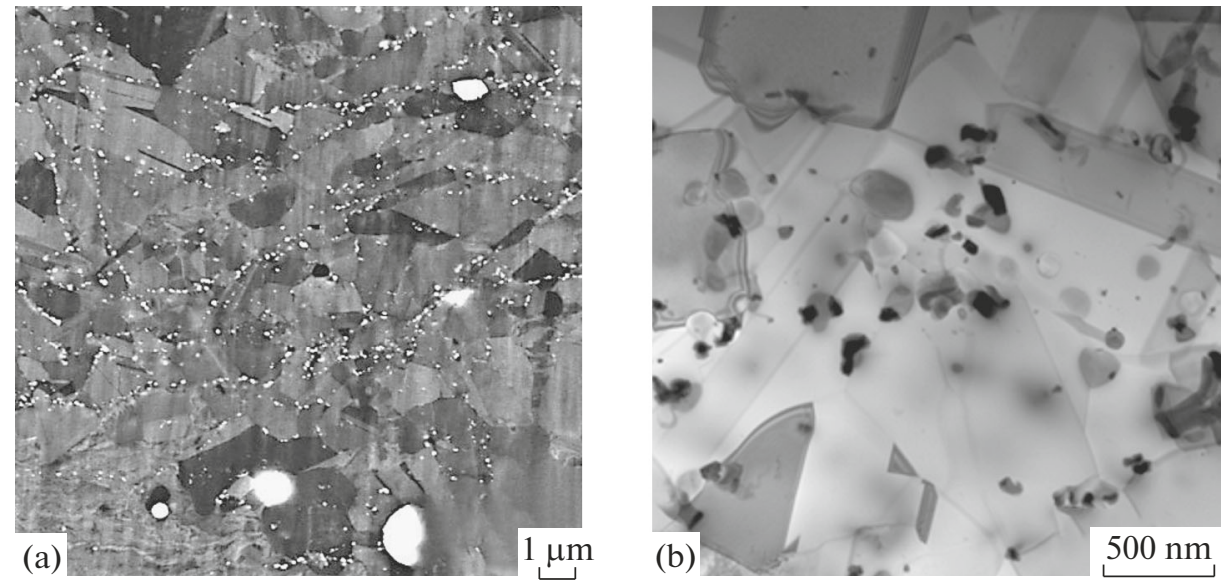

Fig. 3. Recrystallized structure of $\mathrm{Ni}-\mathrm{Cr}-\mathrm{W}$ commercial cast alloy after rolling (80\%) and annealing $750^{\circ} \mathrm{C} / 1 \mathrm{~h}$ : (a) $\mathrm{SEM}$ (dispersion carbide precipitations are light); (b) TEM (dispersion carbide precipitations are dark).
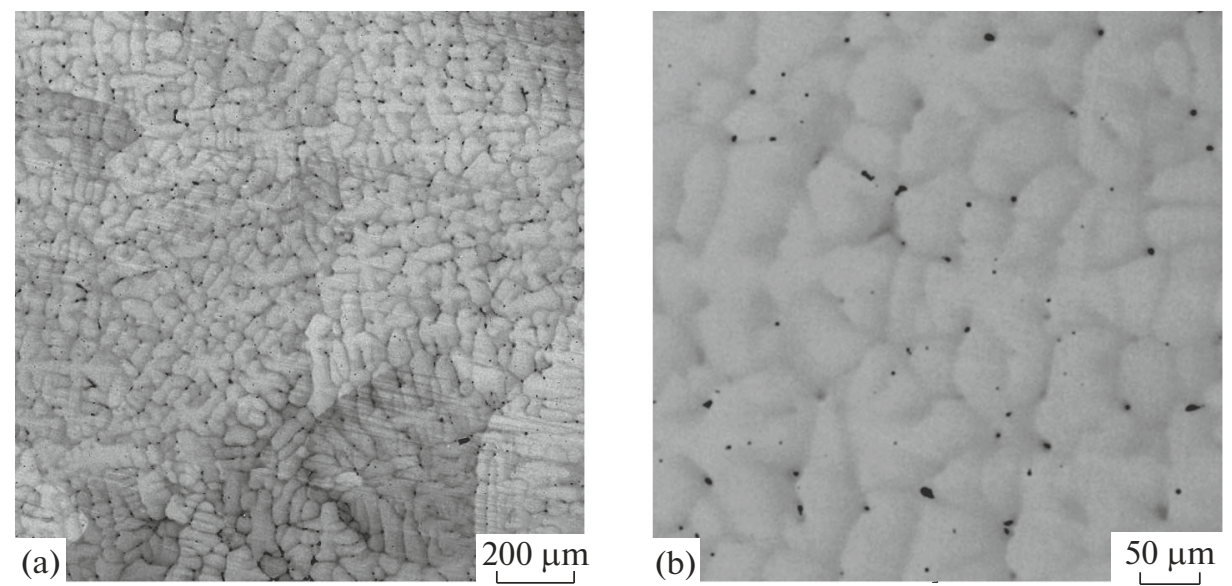

Fig. 4. SEM images of microstructure of the SHS alloy (position III) at different magnifications.
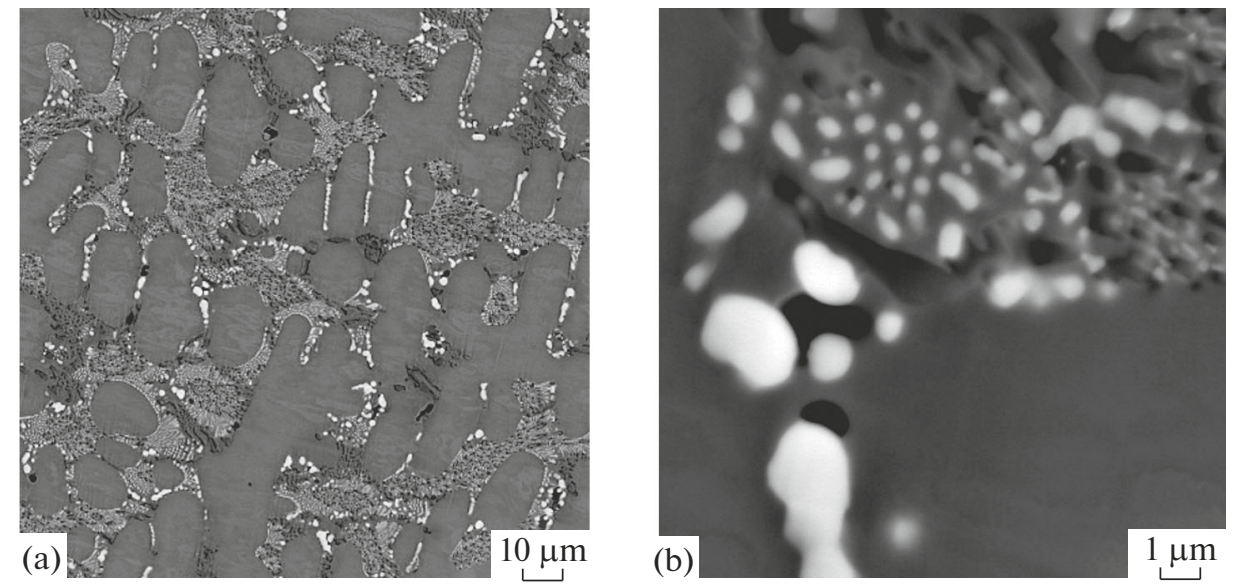

Fig. 5. SEM images of microstructure of the SHS alloy with the addition of $0.1 \mathrm{wt} \% \mathrm{C}$ (position IV) at different magnifications. 
Table 2. Mechanical properties of the cast and SHS Ni-based alloy in various states

\begin{tabular}{|c|c|c|c|}
\hline \multirow[t]{2}{*}{ State } & \multirow{2}{*}{$\begin{array}{l}\text { Microhardness } \\
\text { at room } \\
\text { temperature }\end{array}$} & \multicolumn{2}{|c|}{$\begin{array}{l}\text { Yield stress } \sigma_{0.2} \text { and tensile stress } \sigma_{\mathrm{s}} \\
\text { at the test temperature of } 1000^{\circ} \mathrm{C} \text {; } \\
\text { the test rate is } 10^{-4} \mathrm{~s}^{-1}\end{array}$} \\
\hline & & $\sigma_{0.2}, \mathrm{MPa}$ & $\sigma_{\mathrm{s}}, \mathrm{MPa}$ \\
\hline Initial industrial cast alloy (state I) & 200 & 20 & 50 \\
\hline $\begin{array}{l}\text { Initial industrial cast alloy after rolling for the formation of SMC } \\
\text { structure (state II) }\end{array}$ & 220 & 20 & 35 \\
\hline Alloy fabricated through SHS metallurgy (state III) & 190 & 90 & 120 \\
\hline $\begin{array}{l}\text { Alloy fabricated through SHS metallurgy with addition } \\
\text { of } 0.1 \mathrm{wt} \% \text { powdered carbon (state IV) }\end{array}$ & 260 & 120 & 145 \\
\hline
\end{tabular}

possess increased strength characteristics at room temperature. It is reasonable to suggest that strengthening of the cast alloy after rolling and formation of the SMC structure (state II) is related to grain dispersion, while that of the SHS alloy additionally doped with carbon (state IV) is caused by solid-solution strengthening with carbon, which represents an inclusion impurity.

In the case of SHS alloys, the flow stress at hightemperature tests is significantly higher than in the cast alloys both in the coarse-grain and SMC states. Addition of a small amount of carbon to the SHS alloy enhances the resistance to high-temperature strain owing to the formation of the carbide phase, which restricts the motion of dislocations and grain-boundary creeping. In addition, the dendritic structure of the SHS alloy also provides an increase in the resistance to strain in the direction of elongation of dendrites. It is known that the formation of the dendritic structure is related to the inhomogeneity of the chemical composition of the alloy, which almost always arises during its crystallization (central dendritic domains, which are rich in high-melting components, crystallize first).

Thus, the results of the studies show that the counterpart of VZh98 alloy prepared through SHS metallurgy and additionally alloyed with carbon is the most promising material among the considered materials.

\section{CONCLUSIONS}

Using scanning and transmission electron microscopy, the effect of structural-phase state on the mechanical characteristics of industrial cast heatresistant alloy of the $\mathrm{Ni}-\mathrm{Cr}-\mathrm{W}$ system (VZh98 brand) and counterpart alloys prepared through SHS metallurgy has been compared. It has been determined that a structure in which grain boundaries are fixed by disperse particles is formed in SHS alloys, which increases the strain resistance at high temperatures. Addition of up to $0.1 \mathrm{wt} \%$ carbon to SHS alloy enhances this effect owing to carbide formation and solid-solution strengthening. The SHS alloy doped with carbon possesses higher strength characteristics at room and elevated temperatures.

The process conditions of submicrocrystalline structure formation, which significantly enhances the strength characteristics of the VZh98 industrial cast alloy owing to the formation of nanosized carbide precipitates of globular morphology upon recrystallization, have been developed.

These results indicate the prospects of SHS metallurgy for the fabrication of heat-resistant alloys with improved mechanical characteristics at room and elevated temperatures.

\section{FUNDING}

This work was supported by the Russian Foundation for Basic Research (project no. 18-02-00760) "Investigation of the Principles and Physical Mechanisms of Evolution of Structural-Phase State and Mechanical Characteristics of Heat-Resistant Alloys of the $\mathrm{Ni}-\mathrm{Co}-\mathrm{Cr}-(\mathrm{X})$ System at Diffusion Exchange with Inclusion Atoms with Environment," as well as the thematic map of fundamental research of the Institute of Problems of Chemical Physics of the Russian Academy of Sciences, project no. 0089-2019-0017.

\section{REFERENCES}

1. Kolobov, Yu.R., Kablov, E.N., and Kozlov, E.V., Struktura i svoistva intermetallidnykh materialov s nanofaznym uprochneniem (Structure and Properties of Intermetallic Materials with Nanophase Hardening), Moscow: Mosk. Inst. Stali Splavov, 2008.

2. Reed, R.C., The Superalloys: Fundamentals and Applications, Cambridge: Cambridge Univ. Press, 2006.

3. Kolobov, Yu.R., Valiev, R.Z., Grabovetskaya, G.P., et al., Grain Boundary Diffusion and Properties of Nanostructured Materials, Cambridge: Cambridge Univ. Press, 2007.

4. Askeland, D.R. and Phule, P.P., The Science and Engineering of Materials, Stamford, CT: Cengage Learning, 2005. 
5. ASM Specialty Handbook: Heat-Resistant Materials, Materials Park, OH: ASM Int., 1997.

6. Morozova, G.I., Compensation of imbalance of alloying of refractory nickel alloys, Met. Sci. Heat Treat., 2013, vol. 54, nos. 11-12, pp. 667-671.

7. Lomberg, B.S., Ovsepyan, S.V., Bakradze, M.M., and Mazalov, I.S., High-temperature wrought nickel alloys for advanced gas turbine engines and gas turbine units, Vestn. Mosk. Gos. Tekh. Univ. im. N.E. Baumana, 2011, special issue 2, pp. 98-103.

8. Latyshev, V.B., Heat-resistant wrought weldable alloys for combustion chambers, in Aviatsionnye materialy na rubezhe $X X-X X I$ vekov (Aviation Materials at the Turn of 20th-21st Centuries), Moscow: Vseross. Issled. Inst. Aviats. Mater., 1994, pp. 273-278.

9. Lee, S.Y., Lu, Y.L., Liaw, P.K., Choo, H., et al., Elevated-temperature creep-fatigue crack-growth behavior of HAYNES® 188 superalloy, Key Eng. Mater., 2007, vols. 345-346, pp. 287-290.

10. Kun, B., Rui, H., Jinshan, L., and Lian, Z., Grain refinement of $\mathrm{Ni}-\mathrm{Cr}-\mathrm{W}$ based superalloy by near liquidus casting, Rare Met. Mater. Eng., 2014, vol. 43, no. 1, pp. $1-5$.

11. Merzhanov, A.G., The chemistry of self-propagating high-temperature synthesis, J. Mater. Chem., 2004, vol. 14, no. 12, pp. 1779-1786.

12. Merzhanov, A.G., Self-propagating high-temperature synthesis: Non-equilibrium processes and equilibrium products, Adv. Sci. Technol., 2006, vol. 45, pp. 36-44.

13. Yukhvid, V.I., Modification of SHS-processes, Pure Appl. Chem., 1992, vol. 64, no. 7, pp. 977-988.

14. Sanin, V.N., Ikornikov, D.M., Andreev, D.E., and Yukhvid, V.I., Centrifugal SHS metallurgy of nickel aluminide based eutectic alloys, Russ. J. Non-Ferrous Met., 2014, vol. 55, no. 6, pp. 613-619.

15. Yukhvid, V.I., Alymov, M.I., Sanin, V.N., and Andreev, D.E., SHS metallurgy of Ni-Al-based alloy, Key Eng. Mater., 2016, vol. 684, pp. 353-358.

16. Sanin, V.N., Yukhvid, V.I., Ikornikov, D.M., Andreev, D.E., Sachkova, N.V., and Alymov, M.I., SHS metallurgy of high-entropy transition metal alloys, Dokl. Phys. Chem., 2016, vol. 470, no. 2, pp. 145-149.
17. Sanin, V., Andreev, D., Ikornikov, D., and Yukhvid, V., Cast intermetallic alloys and composites based on them by combined centrifugal casting-SHS process, Open J. Met., 2013, vol. 3, no. 2, pp. 12-24.

18. Yukhvid, V.I., Andreev, D.E., Sanin, V.N., Gorshkov, V.A., and Alymov, M.I., Synthesis of cast composite materials by SHS metallurgy methods, Key Eng. Mater., 2017, vol. 746, pp. 219-232.

19. Sanin, V.N., Ikornikov, D.M., Andreev, D.E., Yukhvid, V.I., Levashov, E.A., and Pogozhev, Yu.S., Cast $\mathrm{NiAl} / \mathrm{Ni}_{20} \mathrm{Al}_{3} \mathrm{~B}_{6}$ composites by centrifugal SHS, Int. J. Self-Propag. High-Temp. Synth., 2014, vol. 23, no. 4, pp. 232-239.

20. Sanin, V.N., Ikornikov, D.M., Andreev, D.E., Yukhvid, V.I., Derin, B., and Yucel, O., Protective $\mathrm{Mo}_{2} \mathrm{NiB}_{2}-\mathrm{Ni}$ coatings by centrifugal metallothermic SHS, Int. J. Self-Propag. High-Temp. Synth., 2015, vol. 24 , no. 3 , pp. $161-170$.

21. Zaitsev, A.A., Sentyurina, Zh.A., Levashov, E.A., Pogozhev, Yu.S., Sanin, V.N., Loginov, P.A., and Petrzhik, M.I., Structure and properties of $\mathrm{NiAl}-\mathrm{Cr}(\mathrm{Co}, \mathrm{Hf})$ alloys prepared by centrifugal SHS casting. 1. Room temperature investigations, Mater. Sci. Eng., A, 2017, vol. 690, pp. 463-472.

22. Zaitsev, A.A., Sentyurina, Zh.A., Levashov, E.A., Pogozhev, Yu.S., Sanin, V.N., and Sidorenko, D.A., Structure and properties of $\mathrm{NiAl}-\mathrm{Cr}(\mathrm{Co}, \mathrm{Hf})$ alloys prepared by centrifugal SHS casting followed by vacuum induction remelting. 2. Evolution of the structure and mechanical behavior at high temperature, Mater. Sci. Eng., A, 2017, vol. 690, pp. 473-481.

23. Kolobov, Yu.R., Bozhko, S.A., Golosova, O.A., Sanin, V.N., Ikornikov, D.M., and Yukhvid, V.I., Fine grained $\mathrm{Co}-\mathrm{Cr}-\mathrm{Mo}$ alloy by combined use of SHS and thermomechanical treatment, Int. J. Self-Propag. HighTemp. Synth., 2015, vol. 24, no. 4, pp. 231-235.

24. GOST (State Standard) 5632-2014: Stainless Steels and Corrosion Resisting, Heat-Resisting and Creep Resisting Alloys, Grades, Moscow: Standartinform, 2015.

Translated by A. Muravev 